\title{
Network pharmacology-based assessment to elucidate the molecular mechanism of anti-diabetic action of Tinospora cordifolia
}

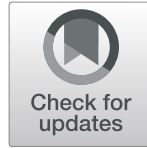

Pukar Khanal ${ }^{1 *}$ D, B. M. Patil', Bijendra K. Mandar ${ }^{1}$, Yadu Nandan Dey² and Taaza Duyu ${ }^{1}$

\begin{abstract}
Background: Tinospora cordifolia is used traditionally for the treatment of diabetes and is used in various formulations. Scientific evidence is also available for its anti-diabetic potency under various animal models. However, the probable molecular mechanism of Tinospora cordifolia in the treatment of diabetes has not been illuminated yet. Hence, the present study dealt to elucidate the probable molecular mechanism of anti-diabetic effect of Tinospora cordifolia using network pharmacology approach.

Methods: The structural information of bioactive phytoconstituents was retrieved from different open source databases. Compounds were then predicted for their hits with the probable targets involved in the diabetes mellitus. Phytoconstituents were also predicted for their druglikeness score, probable side effects, and ADMET profile. The modulated protein pathways were identified by using the Kyoto Encyclopedia of Genes and Genomes pathway analysis. The interaction between the compounds, proteins, and pathways was interpreted based on the edge count. The docking study was performed using Autodock4.0.
\end{abstract}

Results: Nine phytoconstituents from Tinospora cordifolia were identified to modulate the pathogenic protein molecules involved in diabetes mellitus. Among them, tembetarine scored highest druglikeness hit and had the maximum interaction with proteins involved in diabetes. Further, neuroactive ligand-receptor interaction was predicted as majorly modulated pathway.

Conclusion: The current study identified an important antidiabetic constituent, tembetarine which modulated the majority of diabetic proteins majorly modulating neuroactive ligand-receptor interaction.

Keywords: Diabetes mellitus, Network pharmacology, Neuroactive ligand-receptor interaction, Tembetarine, Tinospora cordifolia

\section{Introduction}

Type 2 diabetes mellitus (T2DM) is a metabolic disorder due to insulin insensitivity/insulin resistance; modern pharmacotherapy utilizes synthetic oral hypoglycaemic agents [1]. Although these molecules are effective in the management of elevated blood glucose level, they are not free from numerous side effects like genital mycosis, pancreatitis, ketoacidosis, nausea, vomiting, fractures, and neuropathy risk. GLP-1 agonists (p), like liraglutide, dulaglutide, and exenatide are contraindicated in multiple

\footnotetext{
* Correspondence: pukarkhanal58@gmail.com

${ }^{1}$ Department of Pharmacology and Toxicology, KLE College of Pharmacy, Belagavi, KLE Academy of Higher Education and Research (KAHER), Belagavi 590010, India

Full list of author information is available at the end of the article
}

endocrine neoplasia (MEN) type 2 due to high risk of $\mathrm{C}$ cell tumor in thyroid and pancreatitis [2]. Further, T2DM is a polygenic condition; includes the collaborative task of multifarious pathogenic genes forming a labyrinthine disease network within the biological system [3]. Hence, blocking the task of one protein could trigger another pathway to earn the same response within the disease network. This could be due to the collaborative function of multiple genes in a synergistic pattern to achieve a particular response.

The current synthetic oral hypoglycaemic agents target a specific protein [2]; however, it is to be understood that a single drug can regulate multiple proteins as a "single master key unlocks multiple locks" [4], which 
could be dose-dependent i.e. minimization of dose may not achieve the desired pharmacological response and a higher dose may lead to adverse effects. Hence, for the management of complex disease like diabetes, it may not be advisable to target a single protein molecule; instead, target the multiple proteins with a low dose of multiple compounds and achieve the synergistic effect. Herbal medicines are reported to manage the diabetic condition followed by its symptomatic relief, also prevent the probable complications; via the regeneration of beta-cells, minimization of insulin resistance [5] and lowering the elevated blood glucose level by restoring the liver glycogen level [6]. Multiple herbal medicines and their preparations have been reported to possess the anti-diabetic activity [7]. Further, isolated compounds from traditional folk medicines have also been identified to possess the anti-diabetic activity [8]. However, folk medicine lacks sufficient scientific data in the management of complex diseases like diabetes; be short of evidence in phytoconstituents composition, mechanism of action and ADMET profile.

Tinospora cordifolia, commonly identified as heartleaved moonseed, Guduchi, belongs to the family Menispermaceae is recorded as "Guduchi (St)" in the Ayurvedic Pharmacopoeia of India; utilized in the management of "Prameha" (an ayurvedic term that explains clinical conditions involved in obesity, prediabetes, diabetes mellitus, and metabolic syndrome). Further, Ayurvedic Pharmacopeia of India records terpenoids and alkaloids as a major phytoconstituents in the management of Jvara (Fever), Kustha (Skin disorders), Pandu (Anaemia), Vatarakta (Gout) and Kamala (Jaundice) [9]. Scientific reports have been made for $T$. cordifolia as an anti-diabetic agent in various experimental animal models [10, 11]. However, the probable mechanism of $T$. cordifolia in the management of diabetes has not been illuminated yet. Hence, the present study aims to identify the potential phytoconstituents from $T$. cordifolia, identify their targets involved in diabetes mellitus (DM) and report the probable mechanism in its management via the network pharmacology approach.

\section{Methods}

\section{Mining of phytoconstituents and proteins involved in} diabetes

Phytoconstituents of $T$. cordifolia were mined from the available literature; scientific journals and traditional medicinal books. The database was constructed for the phytoconstituents, their types, SMILES and PubChem CID. The duplication of phytoconstituents was eliminated during the construction of the database. The canonical SMILES and PubChem CID of each phytoconstituents were retrieved from the PubChem Database [12]. SMILES were queried for the prediction of the target in
BindingDB [13] at the percentage similarity of $70 \%$ with known ligand molecules. The proteins involved in diabetes were identified with reference to the known targets of diabetes reported in Therapeutic Target Database (TTD) [14]. Gene ID of each protein molecule identified as the target of diabetes mellitus was retrieved from the UniProt [15].

\section{Druglikeness prediction and ADMET profile}

Phytoconstituents were predicted for the druglikeness score via the utilization of "Lipinski's rule of five" model by using MolSoft (http://www.molsoft.com/). Similarly, admetSAR2.0 [16] was used to predict ADMET profile of individual phytoconstituents.

\section{Prediction of side effects}

ADVERpred [17] was used to predict the probable side effects by querying the SMILES of each phytoconstituent. The mol charge of the phytoconstituents was removed (if present) during the prediction of side effects. The side effects were considered if the probable activity $(\mathrm{Pa})$ is higher than probable inactivity $(\mathrm{Pi})$ and $\mathrm{Pa}$ value greater than 0.7 .

\section{Pathway and network analysis}

Set of proteins involved in DM was queried in STRING [18] and gene enrichment analysis was performed to identify the pathways that are modulated by the phytoconstituents. Further, the KEGG pathway(https://www.genome.jp/ $\mathrm{kegg} /$ ) analysis was performed to identify the pathways involved in DM. Cytoscape [19] 3.5.1 was used to construct the network between phytoconstituents, protein molecules, and identified pathways. The color and node size scale were used to interpret the whole network which is based on the number of edges (edge count). The node with the maximum number of edge count was indicated with colossal node.

\section{Docking studies}

Three-dimensional structure of tembetarine was retrieved from PubChem database and minimized using MMFF94 forcefield [20]. The target molecule beta 1 adrenergic receptor was retrieved from the RCSB (https:// www.rcsb.org/) database. Discovery Studio [21] was used to remove water molecules and heteroatoms from the protein molecule. Similarly, SWISS-MODEL [22] was used for the homology modeling of beta 1 adrenergic receptor by using accession number: NP_000675.1 as a query sequence and PDB ID: 4BVN as a template. AutoDock4.0 [23] was used to predict the binding affinity of tembetarine with beta 1 adrenergic receptor. After docking, the pose scoring the lowest binding energy was chosen to visualize the ligand-protein interaction. 


\section{Results}

Mining of phytoconstituents and proteins involved in diabetes

Thirty-one different phytoconstituents were identified in Tinospora cordifolia from different databases and other open-source records; nine of them were predicted to modulate the diabetic protein molecules (Table 1). These phytoconstituents were identified as alkaloids, terpenes, and steroids. Similarly, the majority of the targeted diabetic protein molecules were surface proteins and enzymes (Fig. 1).

\section{Predictive side effects, ADMET profile, and druglikeness of compounds}

Except for N-E-feruloyl tyramine, all the eight phytoconstituents were predicted for their probable side effects. The probability of side effects for arrhythmia, myocardial infarction, and nephrotoxicity of predicted compounds is shown in Fig. 2. Phytochemicals were predicted for their probability for absorptivity, blood-brain barrier permeability, isoenzyme inhibitory activity, mutagenicity, plasma protein binding affinity, and fish aquatic toxicity. The ADMET profile of each phytoconstituent is represented in heat map (Fig. 3). Similarly, all nine phytoconstituents were predicted for their druglikeness score; the highest was scored by tembetarine (Table 2).

\section{Pathway and network analysis}

Gene set enrichment analysis identified thirteen different pathways; modulated by proteins involved in the DM. The peer interpretation of protein interaction under the KEGG pathway analysis identified four different pathways which are directly linked in the pathogenesis of DM. Among them, neuroactive ligand-receptor interaction was identified to score the highest count of gene sets with the lowest false discovery rate (Table 3). Sixty-seven edges were identified in the drug-protein-pathway network in which fifty-two were target-phytoconstituents interactions and fifteen were target-pathway interaction. The constructed network included thirty-four nodes representing four pathways, twenty-one targets and nine phytoconstituents. Tembetarine scored highest edge count; interaction was found with twelve protein molecules i.e. ACACB, ADRA1D, ADRA2C, ADRB1, DPP4, DRD1, DRD1B, ESR1, HTR2A, HTR2C, KCNA4, and PARP1. Similarly, neuroactive ligand-receptor interaction modulated the highest number of protein molecules i.e. DRD5, ADRB1, DRD1, CNR2, ADRA2C, NR3C1, HTR2A, ADRA1D, and HTR2C. Tembetarine majorly modulated proteins which are involved in neuroactive ligand-receptor interaction pathway i.e. ADRA1D, ADRA2C, ADRB1, DRD1, HTR2A, and HTR2C (Fig. 4). Further, ADRA1D, ADRA2C, ADRB1, CNR2, DRD1, HTR2A, HTR2C, and NR3C1 proteins from neuroactive ligand-receptor interaction pathway were also modulated by other phytoconstituents to show the synergistic effect for anti-diabetic activity.

\section{Docking studies}

The binding affinity and inhibitory constant of tembetarine with beta 1 adrenergic receptor was found to be $6.25 \mathrm{kcal} / \mathrm{mol}$ and $36.45 \mu \mathrm{M}$ respectively. Two hydrogen bond interactions were found in ligand-protein complex i.e. ASN:94 and THR:93 with " $\mathrm{H}$ " atom (hydroxyl group attached to carbon 19) and "O" atom (hydroxyl group attached to carbon 4) respectively (Fig. 5).

\section{Discussion}

Exploration of folk medicines for the management of complex diseases like diabetes via the utilization of network pharmacology is a well-accepted approach. Many attempts have been made to understand the molecular mechanisms of folk medicines in the management of the

Table 1 Types of compounds and their targets

\begin{tabular}{|c|c|c|c|}
\hline Compounds & Compound Type & PubChem CID & Targeted Proteins \\
\hline Tembetarine & Benzyl-iso-quinoline alkaloid & 167718 & $\begin{array}{l}\text { HTR2A,HTR2C,ACACB,ADRB1,ADRA2C,ADRA1D,ESR1,DPP4,DRD1,DRD1B, } \\
\text { PARP1,KCNA4 }\end{array}$ \\
\hline Magnoflorine & Aporphine alkaloid & 73337 & HTR2A,HTR2C,ADRA1D,ADRA2C,ADRB1,DRD1,DRD1B \\
\hline Tinocordiside & Cadinane sesquiterpene glycoside & 177384 & HSD11B2,NR3C1 \\
\hline Tinocordifolioside & $\begin{array}{l}\text { Daucane-type sesquiterpene } \\
\text { glucoside }\end{array}$ & 100926541 & BACE1,ESR1,HSD11B2,HTR2A,HTR2C,NR3C1,NR3C2 \\
\hline Makisterone A & Steroid & 12312690 & BACE1,ESR1,HSD1 1B2,HTR2A,HTR2C,NR3C1,NR3C2 \\
\hline Tetrahydropalmatine & Iso-quinoline alkaloid & 72301 & $\begin{array}{l}\text { ACACB,ADRA1D,ADRA2C,ADRB1,DPP4,DRD1,ESR1,HTR2A,HTR2C,KCNA4, } \\
\text { PARP1 }\end{array}$ \\
\hline $\begin{array}{l}\mathrm{N} \text {-E-feruloyl } \\
\text { tyramine }\end{array}$ & Alkaloid & 5280537 & CNR2 \\
\hline$\beta$-sitosterol & Steroid & 222284 & ESR1, PTPN1 \\
\hline$\gamma$ - sitosterol & Steroid & 457801 & ESR1, PTPN1 \\
\hline
\end{tabular}




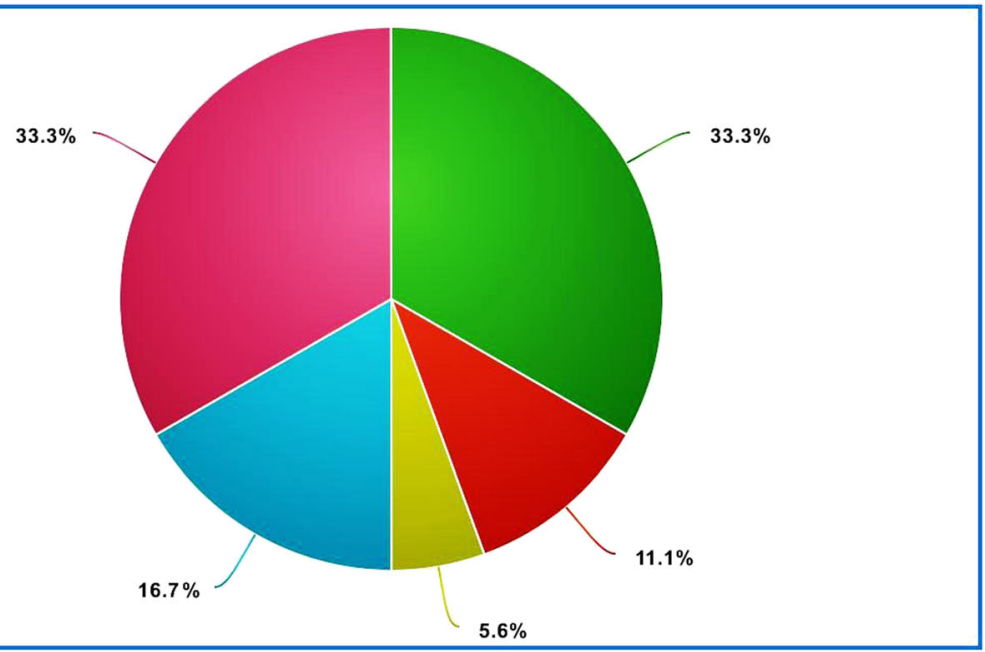

Enzyme $\square$ G protein coupled receptor $\square$ Ion channel $\square$ Nuclear receptor Surface Protein

Fig. 1 Types of protein molecules involved in diabetes

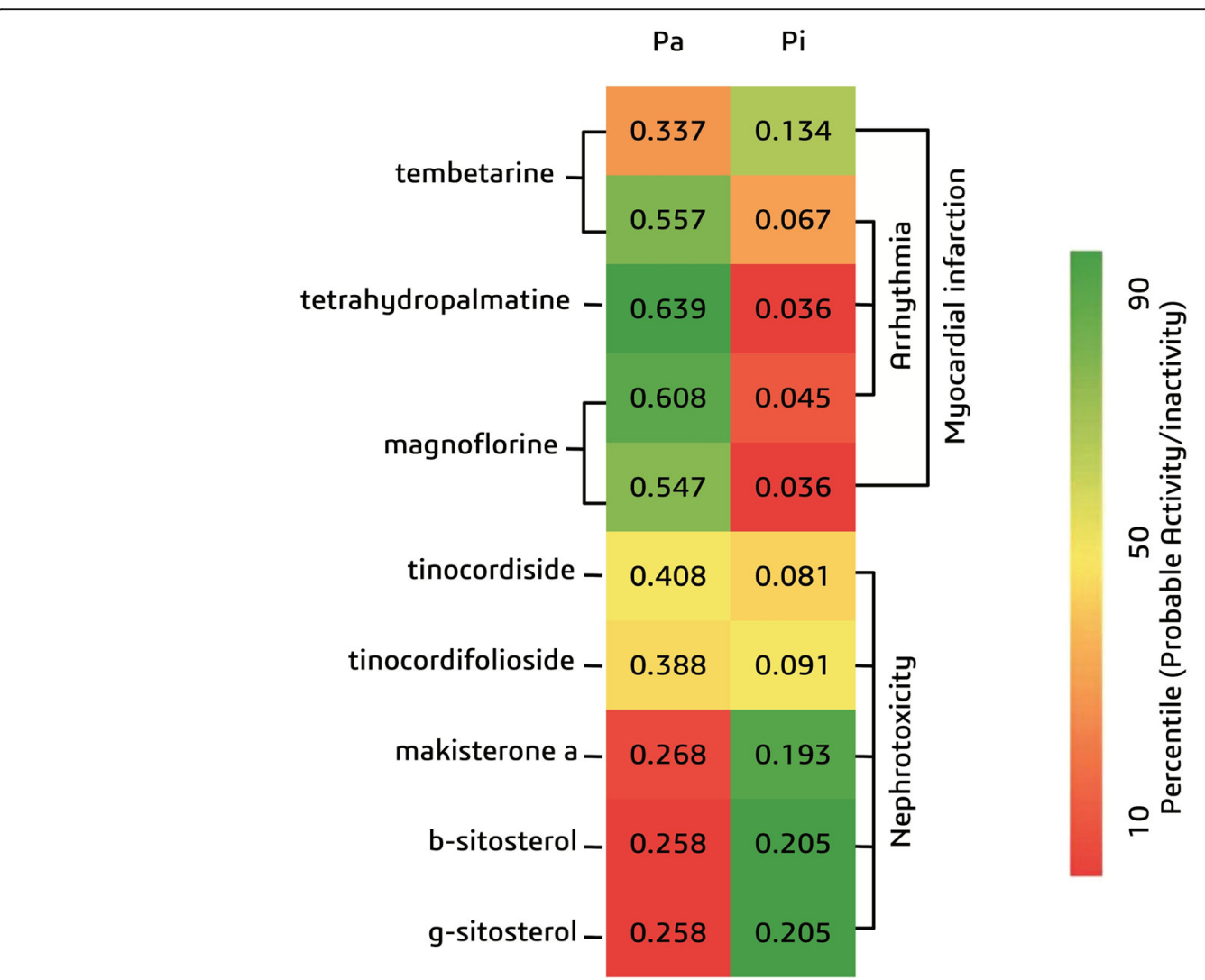

Fig. 2 Probable side effects of phytoconstituents. Pa: Probable activity, Pi: Probable inactivity 


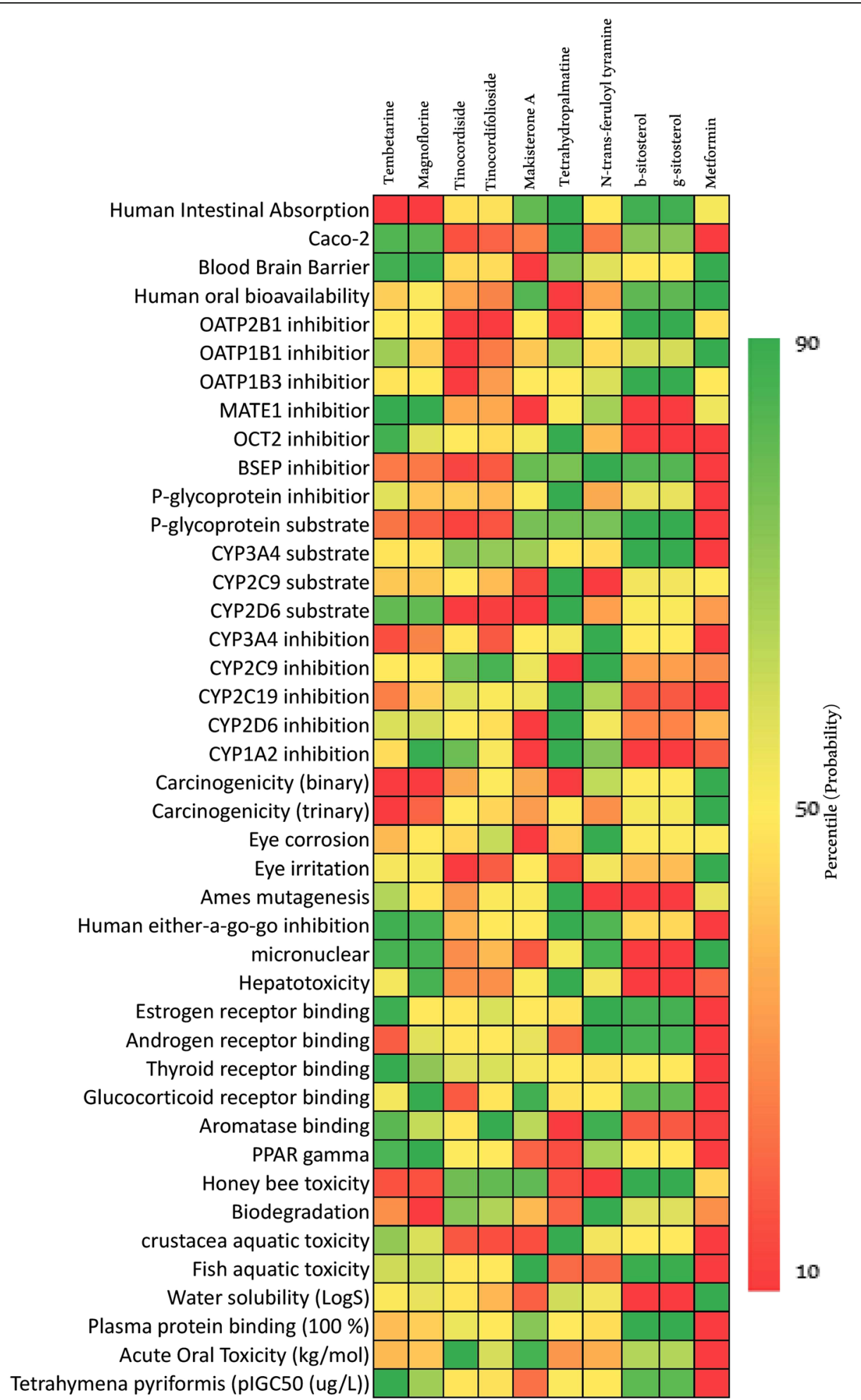

Fig. 3 ADMET profile of phytoconstituents

multifaceted disease by using network pharmacology [24-26]. The utilization of T. cordifolia has been demonstrated for the management of DM [10]. However, the molecular mechanism of $T$. cordifolia in the management of diabetes has not been illuminated clearly. Hence, the current study utilizes the network 
Table 2 Druglikeness property of phytoconstituents

\begin{tabular}{|c|c|c|c|c|c|c|c|c|}
\hline \multirow[t]{2}{*}{ Phytoconstituents } & \multirow{2}{*}{$\begin{array}{l}\text { Molecular } \\
\text { formula }\end{array}$} & \multirow[t]{2}{*}{ MW } & \multirow[t]{2}{*}{ NHBA } & \multirow[t]{2}{*}{$\mathrm{NHBD}$} & \multirow[t]{2}{*}{ MolLogP } & \multicolumn{2}{|l|}{ MolLogS } & \multirow[t]{2}{*}{ DLS } \\
\hline & & & & & & Log (moles/L) & $\mathrm{mg} / \mathrm{L}$ & \\
\hline Tembetarine & $\mathrm{C}_{20} \mathrm{H}_{26} \mathrm{NO}_{4}$ & 344.19 & 4 & 2 & 3.09 & -1.92 & 4120.72 & 1.41 \\
\hline Magnoflorine & $\mathrm{C}_{20} \mathrm{H}_{24} \mathrm{NO}_{4}$ & 342.17 & 4 & 2 & 2.77 & -1.82 & 5225.20 & 0.8 \\
\hline Tinocordiside & $\mathrm{C}_{21} \mathrm{H}_{32} \mathrm{O}_{7}$ & 396.21 & 7 & 4 & 0.98 & -3.42 & 151.88 & 0.47 \\
\hline Tinocordifolioside & $\mathrm{C}_{21} \mathrm{H}_{32} \mathrm{O}_{8}$ & 412.21 & 8 & 4 & 0.08 & -2.44 & 1511.36 & 0.23 \\
\hline Makisterone A & $\mathrm{C}_{28} \mathrm{H}_{46} \mathrm{O}_{7}$ & 494.32 & 7 & 6 & 2.67 & -2.53 & 1442.59 & 1.38 \\
\hline Tetrahydropalmatine & $\mathrm{C}_{21} \mathrm{H}_{25} \mathrm{NO}_{4}$ & 355.18 & 5 & 0 & 2.43 & -4.14 & 26.00 & 1.24 \\
\hline N-E-feruloyl tyramine & $\mathrm{C}_{18} \mathrm{H}_{19} \mathrm{NO}_{4}$ & 313.13 & 4 & 3 & 3.29 & -3.85 & 44.73 & 0.24 \\
\hline$\beta$-sitosterol & $\mathrm{C}_{29} \mathrm{H}_{50} \mathrm{O}$ & 414.39 & 1 & 1 & 9.48 & -7.51 & 0.01 & 0.88 \\
\hline$Y$ - sitosterol & $\mathrm{C}_{29} \mathrm{H}_{50} \mathrm{O}$ & 414.39 & 1 & 1 & 9.48 & -7.51 & 0.01 & 0.88 \\
\hline
\end{tabular}

MW Molecular weight, NHBA Number of Hydrogen Bond Acceptor, NHBD Number of Hydrogen Bond Donor, DLS Druglikeness Score

pharmacology approach to understand the probable molecular mechanisms of $T$. cordifolia in the management of DM.

We constructed the network interaction between phytoconstituents, their targets, and probable pathways. The result reflects terpenes, steroids, and alkaloids as a potential phytoconstituents to interact with multiple protein molecules involved in the pathogenesis of DM. Among them, tembetarine, a benzyl-isoquinoline alkaloid possesses the potential role in the pharmacotherapy of DM by targeting the numerous protein molecules within the network. Ayurvedic Pharmacopoeia of India records terpenoids and alkaloids as major phytoconstituents in T. cordifolia [9]; were involved to modulate the multiple pathogenic protein molecules which are associated with DM.

One of the clinical trials of $T$. cordifolia reports the alkaloids as a potential phytoconstituents in the management of diabetes in T2DM patients [27]. Further, the reports have been found to explain the beneficial role of alkaloids in the management of diabetes and associated complications [28]. This could be due to the prime role of tembetarine with other phytoconstituents by targeting the numerous protein molecules involved in the pathogenesis of DM to work in a synergistic way as demonstrated in the current findings.
Targeting dopamine and serotonin receptors are identified as one of the approaches in the pharmacotherapy of DM $[29,30]$. The present study predicts tembetarine for its maximum druglikeness score (Table 2) and probability to cross the blood-brain barrier (Fig. 3). This suggests the probability of tembetarine to act on the dopamine and serotonin receptors and modulate the glucose homeostasis via the participation in noradrenaline output, appetite control and perpetuating biological clock which directly responds to the pancreatic beta-cell secretion.

The control in the appetite is also one of the important approaches in diabetes management [31]. The current study identifies tembetarine and tetrahydropalmate to inhibit DPP4 (Table 1) and increase the level of incretins suggesting their important role in the appetite control and participation in glucose homeostasis. Further, $T$. cordifolia is reported for its protective effect against insulin resistance and oxidative stress [32] and contribute in improving glucose tolerance in diabetic rats [33]; demonstrated in the current study by modulating ESR1 and PTPN1 proteins by steroids.

KEGG pathway analysis indicated the important role of $T$. cordifolia in the management of diabetes by modulating four major pathways i.e. neuroactive ligandreceptor interaction, aldosterone-regulated sodium reabsorption, insulin resistance, and insulin signaling

Table 3 Gene set Enrichment analysis of proteins involved in diabetes mellitus

\begin{tabular}{lllll}
\hline Pathway & Description & $\begin{array}{l}\text { Count In Gene } \\
\text { Set }\end{array}$ & $\begin{array}{l}\text { False Discovery } \\
\text { Rate }\end{array}$ & Genes \\
\hline hsa04080 & $\begin{array}{l}\text { Neuroactive ligand-receptor } \\
\text { interaction }\end{array}$ & 9 & $4.63 E-11$ & $\begin{array}{l}\text { DRD5, ADRB1, DRD1, CNR2, ADRA2C, NR3C1, HTR2A, } \\
\text { ADRA1D, HTR2C }\end{array}$ \\
hsa04960 & $\begin{array}{l}\text { Aldosterone-regulated sodium } \\
\text { reabsorption }\end{array}$ & 2 & 0.0054 & HSD11B2, NR3C2 \\
hsa04931 & Insulin resistance & 2 & 0.0231 & PTPN1, ACACB \\
hsa04910 Insulin signaling pathway & 2 & 0.0267 & PTPN1, ACACB \\
\hline
\end{tabular}




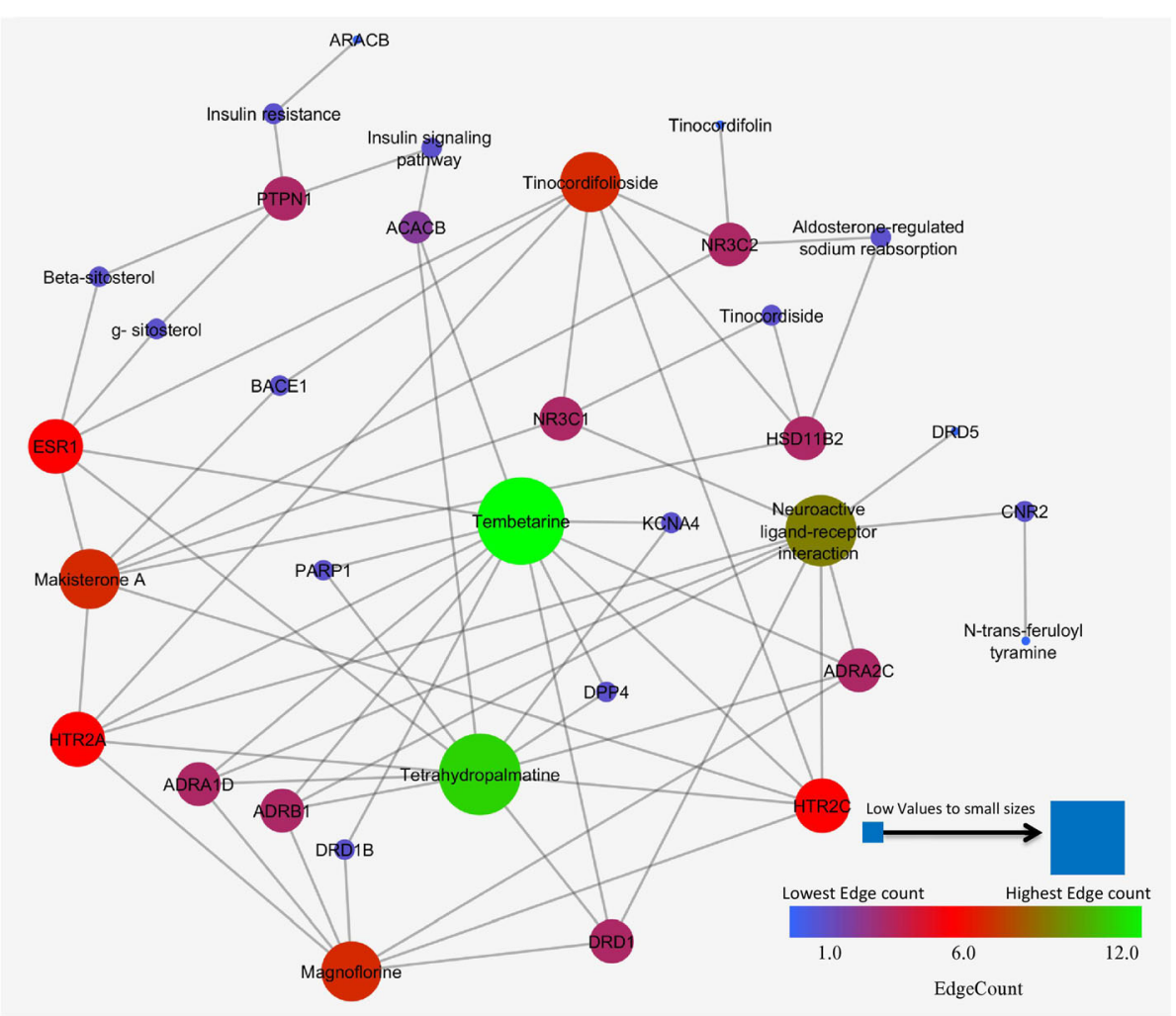

Fig. 4 Network representation of interaction between phytoconstituents, targets and pathways

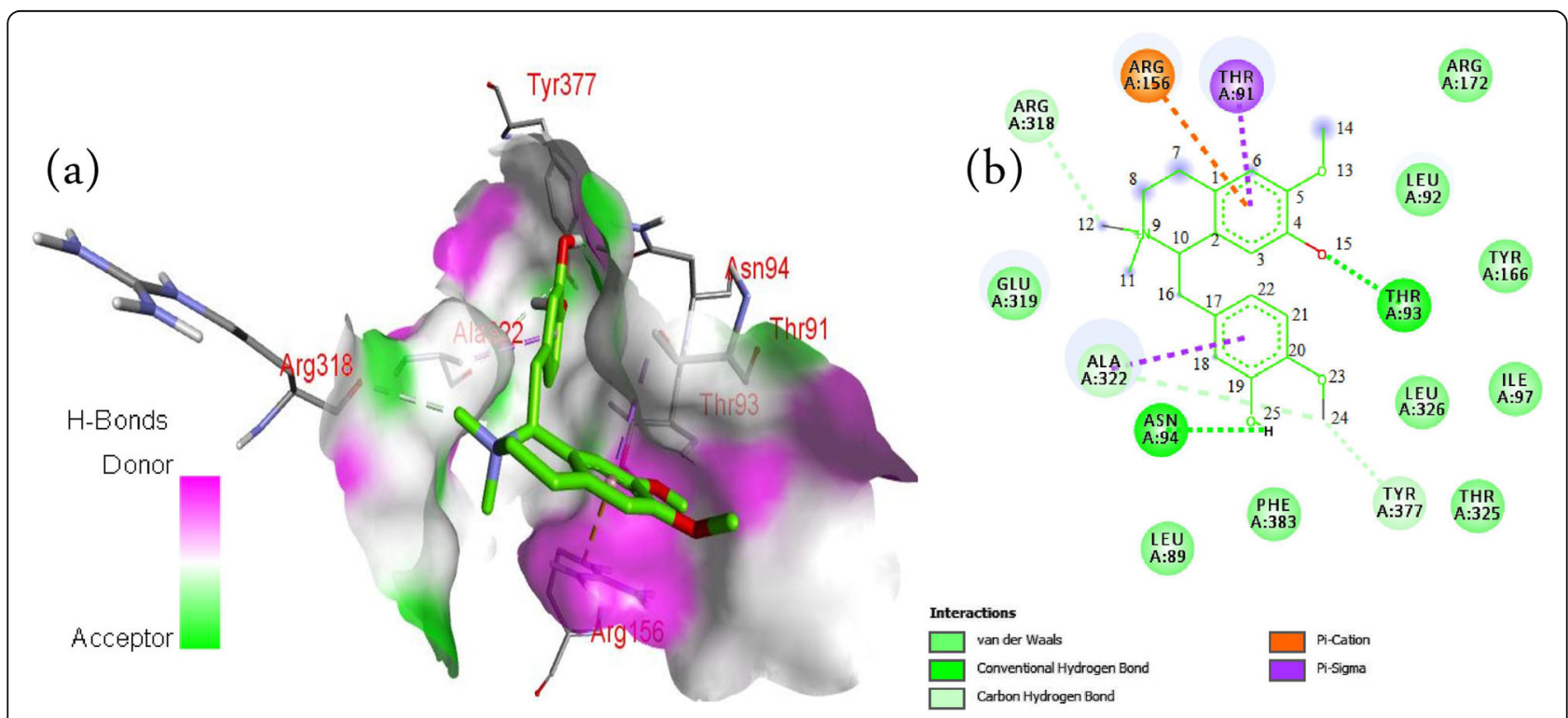

Fig. 5 Interaction of tembetarine with beta 1 adrenergic receptor. (a) 3D pose of tembetarine (b) 2D plot of tembetarine-beta 1 adrenergic receptor interaction 
pathway. KEGG pathway records neuroactive ligandreceptor interaction as one of the major pathways for leptin deficiency (KEGG Entry: H02059), leptin receptor deficiency (KEGG Entry: H02060), and genetic obesity (KEGG Entry: H02106, [34]). Leptin deficiency is one of the major reasons due to the uncontrolled diabetic condition [35] leading to unregulated appetite, thermogenesis, elevated hepatic gluconeogenesis and lowered glucose uptake expounding the shape of insulin resistance [36]. Aldosterone-regulated sodium reabsorption is associated with insulin-resistant diabetes mellitus with acanthosis nigricans (KEGG Entry: H01228) [37]. In the current study, two genes i.e. PTPN1 and ACACB were identified to be regulated which are involved in the insulin resistance/signaling. PTPN1 is identified to eradicate phosphate groups from phosphorylated tyrosine residues and is involved in T2DM and insulin resistance [38]. $\mathrm{ACACB}$ inhibits glucose and fatty acid oxidation and enhances the storage of fat. It also regulates the oxidation of fatty acid in mitochondria via the inhibition of carnitine palmitoyltransferase 1 ; proves imperative character in diabetic and obese conditions [39].

The in vitro and in vivo studies reflect the potency of alkaloids and steroids from $T$. cordifolia play a crucial role in the management of diabetes [40]. The previous report suggests the insulin sensitivity efficacy of $T$. cordifolia [41, 42] which could be due to the interaction of $\beta / \gamma$-sitosterol with PTPN1 and ACACB (Table 1). Further, alkaloid rich fraction has been reported to minimize the elevated blood glucose level via the insulin mimicking and insulinreleasing effect [40]. The current study identifies modulation of neuroactive ligand-receptor interaction (KEGG Entry: hsa04080) via the majority of the phytoconstituents including tembetarine; modulates secretins e.g. glucagon and glucagon-like peptide (GLP) which are wellacknowledged for insulin sensitization. This suggests alkaloids from $T$. cordifolia modulate the insulin sensitivity via neuroactive ligand-receptor interaction.

Insulin resistance and T2DM are the major contributing factors in the cardiomyopathy [43] which is one of the risk factors in diabetic complications. Beta 1 adrenergic receptor is reported to activate phospholamban in myocytes and eNOS in myocytes [44]; phospholamban decreases muscle relaxation and cardiac contractility [45]; decreases heart rate and stroke volume respectively and eNOS maintains vascular tone [46]. The role of neuroactive ligand-receptor interaction in the cardioprotection has been reported [47]. In the current finding, three different phytoconstituents i.e. tembetarine, tetrahydropalmatine, and magnoflorine were identified to interact with ADRB1; one of the protein molecules from neuroactive ligand-receptor interaction. Hence, the reported cardioprotective effects of $T$. cordifolia $[48,49]$ could be due to the interaction with ADRB1 and neuroactive ligand-receptor interaction. This finding is further supported by the mining of protein targets which identified ADRB1 as a potential target for tembetarine.

In conclusion, we identified tembetarine as one of the major alkaloids to interact with the maximum number of protein molecules that are involved in the pathogenesis of DM. Further, neuroactive ligand-receptor interaction was identified as a major pathway in the management of diabetes and cardio-protection which is one of the major risks in insulin resistance and diabetes. However, the current findings are only based on processor simulations which need to be demonstrated via wet-lab protocols.

\section{Abbreviations \\ ADMET: Absorption Distribution Metabolism Excretion and Toxicity; DM: Diabetes Mellitus; DPP4: Dipeptidyl peptidase-4; eNOS: Endothelial nitric oxide synthase; GLP: glucagon like peptide; KEGG: Kyoto Encyclopedia of Genes and Genomes; MEN: Multiple endocrine neoplasia; MMFF94: Merck Molecular Force Field 94; Pa: Probable activity; Pi: Probable inactivity; RCSB: Research Collaboratory for Structural Bioinformatics; SMILES: Simplified molecular-input line-entry system; STRING: Search Tool for the Retrieval of Interacting Genes/Proteins; T2DM: Type 2 Diabetes Mellitus}

\section{Acknowledgements}

The authors are thankful Dr. N. A. Khatib, Associate Professor and Head of Department, Department of Pharmacology for his support and encouragement of work. The authors are also thankful to Ms. Jyoti K for her assistance during data mining.

\section{Authors' contributions}

PK performed the review of literature, performed work and wrote the manuscript. Prof. BMP designed the study protocol and helped in the data interpretation. BKM retrieved the data from open source database, involved in the summarization of literature relevant to the study and helped in drafting the manuscript. YND and TD have equal role in interpretation of result and manuscript review. All authors read and approved the final manuscript.

\section{Funding}

The authors have no support or funding to report.

Availability of data and materials

The datasets analyzed during the current study are available from Pukar Khanal (corresponding author) on request.

Ethics approval and consent to participate Not applicable.

Consent for publication

Not applicable.

\section{Competing interests}

The authors declare that they have no competing interest.

\section{Author details}

'Department of Pharmacology and Toxicology, KLE College of Pharmacy, Belagavi, KLE Academy of Higher Education and Research (KAHER), Belagavi 590010, India. ${ }^{2}$ ICMR-National Institute of Traditional Medicine, Belagavi 590010, India.

Received: 12 August 2019 Accepted: 29 October 2019

\section{References}

1. Prabhakar PK, Doble M. Effect of natural products on commercial oral antidiabetic drugs in enhancing 2-deoxyglucose uptake by 3T3-L1 adipocytes. Ther Adv Endocrinol Metab. 2011;2:103-4. 
2. Chaudhury A, Duvoor C, Dendi R, Sena V, Kraleti S, Chada A, Ravilla R, Marco A, Shekhawat NS, Montales MT, Kuriakose K. Clinical review of antidiabetic drugs: implications for type 2 diabetes mellitus management. Front Endocrinol. 2017:8:6.

3. Sacks DB, McDonald JM. The pathogenesis of type II diabetes mellitus: a polygenic disease. Am J Clin Pathol. 1996;105:149-56.

4. Chandran U, Mehendale N, Tillu G, Patwardhan B. Network pharmacology of ayurveda formulation Triphala with special reference to anti-cancer property. Comb Chem High Throughput Screen. 2015;18:846-54.

5. Choudhury H, Pandey M, Hua CK, Mun CS, Jing JK, Kong L, Ern LY, Ashraf NA, Kit SW, Yee TS, Pichika MR. An update on natural compounds in the remedy of diabetes mellitus: a systematic review. J Tradit Complement Med. 2018:8:361-76

6. Rao VP, Madhavi K, Naidu DM, Gan SH. Rhinacanthus nasutus improves the levels of liver carbohydrate, protein, glycogen, and liver markers in streptozotocin-induced diabetic rats. Evid Based Complement Alternat Med. 2013;2013:102901.

7. Li WL, Zheng HC, Bukuru J, De Kimpe N. Natural medicines used in the traditional chinese medical system for therapy of diabetes mellitus. J Ethnopharmacol. 2004;92:1-21.

8. Chen J, Mangelinckx S, Adams A, Wang ZT, Li WL, De Kimpe N. Natural flavonoids as potential herbal medication for the treatment of diabetes mellitus and its complications. Nat Prod Commun. 2015;10:187-200.

9. The Ayurvedic Pharmacopoeia of India. Ministry of Health and Family Welfare, Department of AYUSH. Government of India. 2016;Part-1, Volume -1:53.

10. Sharma R, Amin H, Prajapati PK. Antidiabetic claims of Tinospora cordifolia (wild.) Miers: critical appraisal and role in therapy. Asian Pac J Trop Biomed. 2015;5:68-78.

11. Puranik N, Kammar KF, Devi S. Anti-diabetic activity of Tinospora cordifolia (Willd.) in streptozotocin diabetic rats; does it act like sulfonylureas? Turkish J Med Sci. 2010;40:265-70.

12. Kim S, Thiessen PA, Bolton EE, Chen J, Fu G, Gindulyte A, Han L, He J, He S, Shoemaker BA, Wang J. PubChem substance and compound databases. Nucleic Acids Res. 2015;44:D1202-13.

13. Gilson MK, Liu T, Baitaluk M, Nicola G, Hwang L, Chong J. BindingDB in 2015: a public database for medicinal chemistry, computational chemistry and systems pharmacology. Nucleic Acids Res. 2016;44:D1045-53.

14. Li YH, Yu CY, Li XX, Zhang P, Tang J, Yang Q, Fu T, Zhang X, Cui X, Tu G, Zhang $Y$. Therapeutic target database update 2018: enriched resource for facilitating bench-to-clinic research of targeted therapeutics. Nucleic Acids Res. 2017:46:D1121-7.

15. Consortium U. The universal protein resource (UniProt). Nucleic Acids Res. 2007:36:D190-5.

16. Yang H, Lou C, Sun L, Li J, Cai Y, Wang Z, Li W, Liu G, Tang Y. admetSAR 2.0: web-service for prediction and optimization of chemical ADMET properties. Bioinformatics. 2018;35:1067-9.

17. Ivanov SM, Lagunin AA, Rudik AV, Filimonov DA, Poroikov W. ADVERPredweb service for prediction of adverse effects of drugs. J Chem Inf Model. 2017:58:8-11.

18. Szklarczyk D, Morris JH, Cook H, Kuhn M, Wyder S, Simonovic M, Santos A, Doncheva NT, Roth A, Bork P, Jensen LJ. The STRING database in 2017 quality-controlled protein-protein association networks, made broadly accessible. Nucleic Acids Res. 2016:45:D362-8.

19. Shannon P, Markiel A, Ozier O, Baliga NS, Wang JT, Ramage D, Amin N, Schwikowski B, Ideker T. Cytoscape: a software environment for integrated models of biomolecular interaction networks. Genome Res. 2003;13:2498-504

20. Halgren TA. Merck molecular force field. I. Basis, form, scope, parameterization, and performance of MMFF94. J Comput Chem. 1996:17:490-519.

21. Systèmes D. BIOVIA discovery studio modeling environment. San Diego: Dassault Systèmes Biovia; 2016.

22. Schwede T, Kopp J, Guex N, Peitsch MC. SWISS-MODEL: an automated protein homology-modeling server. Nucleic Acids Res. 2003;31:3381-5

23. Morris GM, Goodsell DS, Halliday RS, Huey R, Hart WE, Belew RK, Olson AJ. Automated docking using a Lamarckian genetic algorithm and an empirical binding free energy function. J Comput Chem. 1998;19:1639-62.

24. Khanal P, Patil BM. Gene set enrichment analysis of alpha-glucosidase inhibitors from Ficus benghalensis. Asian Pac J Trop Biomed. 2019:9:263-70.

25. Sidders B, Karlsson A, Kitching L, Torella R, Karila P, Phelan A. Network-based drug discovery: coupling network pharmacology with phenotypic screening for neuronal excitability. J Mol Biol. 2018;430:3005-15.
26. Zhang GB, Li QY, Chen QL, Su SB. Network pharmacology: a new approach for chinese herbal medicine research. Evid Based Complement Alternat Med. 2013;2013:621423.

27. Kumar V, Mahdi F, Singh R, Mahdi AA, Singh RK. A clinical trial to assess the antidiabetic, antidyslipidemic and antioxidant activities of Tinospora cordifolia in management of type-2 diabetes mellitus. Int J Pharm Sci Res. 2016;7:757-64.

28. Grover JK, Yadav S, Vats V. Medicinal plants of India with anti-diabetic potential. J Ethnopharmacol. 2002;81:81-100.

29. Vicchi FL, Luque GM, Brie B, Nogueira JP, Tornadu IG, Becu-Villalobos D. Dopaminergic drugs in type 2 diabetes and glucose homeostasis. Pharmacol Res. 2016;109:74-80.

30. Oh CM, Park S, Kim H. Serotonin as a new therapeutic target for diabetes mellitus and obesity. Diabetes Metab J. 2016:40:89-98.

31. Forouhi NG, Misra A, Mohan V, Taylor R, Yancy W. Dietary and nutritional approaches for prevention and management of type 2 diabetes. BMJ. 2018; $361: k 2234$

32. Reddy SS, Ramatholisamma P, Karuna R, Saralakumari D. Preventive effect of Tinospora cordifolia against high-fructose diet-induced insulin resistance and oxidative stress in male Wistar rats. Food Chem Toxicol. 2009:47:2224-9.

33. Nadig PD, Revankar RR, Dethe SM, Narayanswamy SB, Aliyar MA. Effect of Tinospora cordifolia on experimental diabetic neuropathy. Indian 」 Pharmacol. 2012;44:580-3.

34. KEGG Pathway. Pathway Entry: hsa04080. [Internet]. (Accessed on 23 Feb 2019) https://www.genome.jp/dbget-bin/www_bget?hsa04080

35. German JP, Wisse BE, Thaler JP, Oh S, Sarruf DA, Ogimoto K, Kaiyala KJ, Fischer JD, Matsen ME, Taborsky GJ, Schwartz MW. Leptin deficiency causes insulin resistance induced by uncontrolled diabetes. Diabetes. 2010;59:1626-34.

36. Denroche HC, Huynh FK, Kieffer TJ. The role of leptin in glucose homeostasis. J Diabetes Investig. 2012;3:115-29.

37. KEGG Pathway. Pathway Entry: map 04960. [Internet]. (Accessed on 23 Feb 2019) https://www.genome.jp/dbget-bin/www_bget?pathway:map04960

38. Kennedy BP. Role of protein tyrosine phosphatase-1B in diabetes and obesity. Biomed Pharmacother. 1999;53:466-70.

39. Colbert CL, Kim CW, Moon YA, Henry L, Palnitkar M, McKean WB, Fitzgerald K, Deisenhofer J, Horton JD, Kwon HJ. Crystal structure of spot 14, a modulator of fatty acid synthesis. Proc Natl Acad Sci U S A. 2010;107:18820-5.

40. Patel MB, Mishra S. Hypoglycemic activity of alkaloidal fraction of Tinospora cordifolia. Phytomedicine. 2011;18:1045-52.

41. Kalekar SA, Munshi RP, Bhalerao SS, Thatte UM. Insulin sensitizing effect of 3 Indian medicinal plants: an in vitro study. Indian J Pharmacol. 2013:45:30-3.

42. Sangeetha MK, Raghavendran HR, Gayathri V, Vasanthi HR. Tinospora cordifolia attenuates oxidative stress and distorted carbohydrate metabolism in experimentally induced type 2 diabetes in rats. J Nat Med. 2011:65:544-50.

43. Wang J, Song Y, Wang Q, Kralik PM, Epstein PN. Causes and characteristics of diabetic cardiomyopathy. Rev Diabet Stud. 2006:3:108-17.

44. Myagmar BE, Flynn JM, Cowley PM, Swigart PM, Montgomery MD, Thai K, Nair D, Gupta R, Deng DX, Hosoda C, Melov S. Adrenergic receptors in individual ventricular myocytes: the beta- 1 and alpha- $1 \mathrm{~b}$ are in all cells, the alpha-1a is in a subpopulation, and the beta- 2 and beta- 3 are mostly absent. Circ Res. 2017;120:1103-15.

45. MacLennan DH, Kranias EG. Calcium: Phospholamban: a crucial regulator of cardiac contractility. Nat Rev Mol Cell Biol. 2003:4:566-77.

46. Sandoo A, van Zanten JJ, Metsios GS, Carroll D, Kitas GD. The endothelium and its role in regulating vascular tone. Open Cardiovasc Med J. 2010:4:302-12

47. Wang J, Cheng J, Zhang C, Li X. Cardioprotection effects of sevoflurane by regulating the pathway of neuroactive ligand-receptor interaction in patients undergoing coronary artery bypass graft surgery. Comput Math Methods Med. 2017:2017:3618213.

48. Sharma AK, Kishore K, Sharma D, Srinivasan BP, Agarwal SS, Sharma A, Singh SK, Gaur S, Jatav VS. Cardioprotective activity of alcoholic extract of Tinospora cordifolia (Wild.) Miers in calcium chloride-induced cardiac arrhythmia in rats. J Biomed Res. 2011;25:280-6.

49. Rao PR, Kumar VK, Viswanath RK, Subbaraju GV. Cardioprotective activity of alcoholic extract of Tinospora cordifolia in ischemia-reperfusion induced myocardial infarction in rats. Biol Pharm Bull. 2005:28:2319-22.

\section{Publisher's Note}

Springer Nature remains neutral with regard to jurisdictional claims in published maps and institutional affiliations. 